\title{
Accelerating Learners' Self-confidence Level in Second Language Acquisition: A Qualitative Study
}

\author{
Md Rabiul Alam ${ }^{1 *}$, Sultana Jahan², Md Rashed Khan Milon ${ }^{3}$, Diana Ansarey ${ }^{4}$ Sheaikh Umar \\ Faruque Al Hadi ${ }^{5}$ \\ ${ }^{1}$ Department of Language and Literacy Education, University of Malaya, Malaysia \\ ${ }^{2}$ Department of Language and Communication, Patuakhali Science and Technology University, \\ Bangladesh \\ ${ }^{3}$ Department of English, Port City International University, Bangladesh \\ ${ }^{4}$ Department of English, University of Malaya, Malaysia \\ ${ }^{5}$ Department of English, Asian University of Bangladesh, Bangladesh \\ *Corresponding author; Email: rabiulalam.um@gmail.com
}

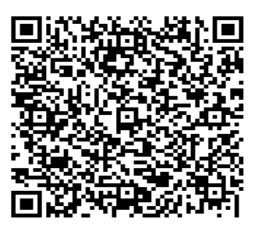

Received: 10 February 2021

Accepted: $\quad 30$ July 2021

$1^{\text {st }}$ Revision: 05 April 2021

$2^{\text {nd }}$ Revision: 12 June 2021

Available Online: 23 August 2021

Published: 23 August 2021

Volume-2, Issue-3

Cite This: ICRRD Qual. Ind. Res. J. 2021, 2(3), 141-153

\begin{abstract}
Second Language Acquisition (SLA) is a complex psychosomatic process. As per educational psychology, its acquisition process depends on some affective determinants related to learners' self-confidence that accelerates learners' zeal of learning the language. However, studies are rare to empirically explore the factors or the ways that help learners build their selfconfidence level. Thus, the prime focus of this study is to find out factors associated with accelerating learners' self-confidence in SLA through a qualitative case study. Data have been collected through semi-structured interviews carried out over phone due to the COVID-19 pandemic. A total of 13 respondents ( 7 boys and 6 girls) have been interviewed who have recently completed their postgraduation. The obtained data have been analyzed with the help of the content analysis technique. The study finds that self-confidence of a learner gets accelerated by three main factors like motivational factor, social factor, and environmental factor which motivate a learner to learn L2. Based on the findings, some policy recommendations have been suggested to further improve $L 2$ learners' self-confidence level.
\end{abstract}

Keywords: SLA; self-confidence; motivational factor; social factor; environmental factor; teachers' role

\section{INTRODUCTION}

Self-confidence and second language acquisition is very intrinsically connected with each other. Not only that, any kind of learning, success, achievement, and prosperity are greatly influenced by self- confidence. It is a kind of inner force that allows people to work spontaneously (Rastelli, 2018) which has been a major part of research for many decades in different fields (Chemers et al., 2000). Research has shown that learners with high self-confidence can acquire second language or L2 
faster than those who have lack of self-confidence (Bao \& Liu, 2021). Scholars have defined self confidence in a number of ways. Believing in the capability to perform the action is the basis of selfconfidence (Chemers et al., 2000; Clark et al., 2008). The term self-confidence refers to self-esteem (Douglas, 2014). Erol and Orth (2011) say that self-esteem is an assessment based on emotions of one's self value or worth. It is the feeling of self-value by oneself while personal judgment is driven externally (Park and Crocker, 2005; Douglas, 2014). Self-confidence or self-esteem in SLA refers to that driving force that makes the learners different from others by enabling them to achieve the L2 in a speedy manner (Islam, 2017). While people learn something and gain feedback from his task by implementing it, they feel like capable of doing the thing and this ability grows their self-confidence (Park et al., 2007; Kung, 2019). So, self-confidence is the result of one's belief of accomplishing the specific task (Bandura, 1993). On the contrary, learners without self-confidence or having low selfconfidence are seen to be nervous, ashamed, timid and introvert who cannot express their feelings, emotions, desires, likings, dis-likings, and what is going on in their mind confidently before others in the target language English (Wang \& Wu, 2020).

Considering the importance of the influence of self-confidence in the acquisition of SLA, many studies (e.g., Maftoon \& Ziafar, 2013; Lenahan, 2015; Selvi \& Martin-Beltrán, 2016; Islam, 2017; Rastelli, 2018; Kung, 2019; Wang \& Wu, 2020; Bao \& Liu, 2021) have been carried out by the scholars throughout the world. They have analysed self-confidence based on many general factors. But there are very few studies that empirically highlighted how to augment L2 learners' self-confidence in the context of tertiary level students in Bangladeshi private universities. Thus, this study aims at tracing out the very rarely touched factors which can build self-confidence of the learners. It will create an awareness in the arena of SLA. Teachers of SLA will come to know how to grow self-confidence of the learners. The study would get importance as it would go for practical data collection along with analysing the literatures related to the influence of self confidence in the acquisition of L2. Based on the objective of this study, a qualitative case study has been carried out where 13 postgraduate students from two prominent private universities in Bangladesh have been interviewed through semistructured interview questions. Due to the COVID-19 pandemic, interviews have been carried out over phone. The obtained data have been analyzed with the help of the content analysis technique. The study finds that self-confidence of a learner gets accelerated by three main factors like motivational factor, social factor, and environmental factor which motivate a learner to learn L2. Based on the findings, some policy recommendations have been suggested to further improve L2 learners' selfconfidence level.

\section{LITERATURE REVIEW}

In the life of human being, self-confidence means a lot through which one can reach the zenith of his success. Every success is the result of self-confidence if we analyse it very keenly. Because, before success appears, one needs to start working first and he or she will never commence the work unless he feels motivated and is driven by self-confidence to that particular work. Similarly, in the acquisition of $L 2$, self-confidence has been an undeniable part which absence makes the learners split from the goal. Many studies have been carried out and many models and theories have been taken place showing the necessity of self confidence in the acquisition of SLA. In the primary stage of L2 learning, self-confidence has been considered as an affective factor on attitudes and motivation with a social psychological approach that determines L2 achievement (Ozdemir \& Papi, 2021; Ghasemi, 
2018; Clément, 1980; 1985; Gardner et al., 1997). Those learners can acquire better communicative competence who are comparatively more confident (Ozdemir \& Papi, 2021; Clément \& Kruidenier, 1985).

Rubio (2007) defines self-confidence as a feeling of self-competence that an individual requires for overcoming the fundamental problems of life. Timirli et al. (2013) define self-confidence as self-esteem and self-assessment of a person through which he can make the task happen. Selfconfidence is a driving force that is generated in every human being from his/her early childhood and it consists of two things: lovability and confidence (Mutluer, 2006). Self-confidence plays the role as a main driving force in L2 acquisition. $L 2$ achievement depends on the higher self-esteem. According to Rubio (2007), there is a correlation between self-confidence and academic achievement. Cultural background of the learners also influences self-confidence (Ghasemi et al., 2020; Dessi and Zhao, 2011; Heine et al., 2001).

Besides, L2 learners' social constructive perspective also determines self-confidence. Norton $(1995 ; 1997 ; 2000)$ says that self-confidence is the result of social and lived experiences of the learners which may take changes in the course of time and space. The concept of self-confidence by Norton shows the relationship and a theoretical framework of social context in SLA that implies social context can influence L2 acquisition both positively and negatively (e.g., Maclntyre \& Vicze, 2017; Maclntyre et al., 2019; Norton, 1997; Pavlenko, 2002; Pennycook, 1999; Zhu et al., 2007). It also refers to the sociocultural theory of L2 learning by Zuengler and Miller (2006).

From Norton's theoretical concept of self-confidence, L2 acquisition is seen to be the outcome of sociocultural engagement. This sociocultural concept shows that $L 2$ acquisition takes place when the learners are engaged culturally, socially and politically with the L2 community (Sugita McEown et al., 2017; Young, 2007; Zhu, et al., 2007; Zuengler \& Miller, 2006). Recent studies on L2 show that learners' active engagement in $L 2$ learning proves their investment. Instead of motivation, the term investment has been used by Norton $(1995$, p.17) in neoclassical economics indicating that if the learners invest in a L2, they do it consciously that they will learn a vast symbolic and material resources. By this way, they arbitrarily relate themselves with the social world (Barkhuizen, 2004). Norton (2000) says that investment in the target language means the investment in the learners' identity which is changeable in the course of time and space. Sociocultural concept of L2 means the influence of environment that helps build learners' self-confidence (Sugita McEown et al., 2017).

This concept of social cultural theory has been considered for many studies, especially in the context of L2 learners while they are using this to achieve their desired target and overcome hindrances in various discourses of learning (Arkoudis \& Davison, 2008; Lin et al., 2002; Norton \& Gao, 2008). The relationship between linguistic competence and individual social status forms the realization of ownership of English in L2 learning (Bourdieu (1991). Feeling the ownership of anything always functions as a great motivational force that, in turns, helps build self-confidence and selfesteem in an individual; and these forces together accelerate their way of achieving their desired goal, L2 acquisition. Lin et al. (2002) describe how the feeling of being non-native speaker of a novice English teacher leads him or her to demotivation at the beginning of his or her teaching, but gradually he/she can overcome this negative feeling. From poststructuralist point of view, language ideologies are very closely related to the lack of potential identity crisis and linguistic legitimacy (Pavlenko, 2002). Language ideologies are very much related to the outlook of individual speaker to his/her language, 
rather it focuses much on the factors that form values and beliefs in social, local and global contexts. Pavlenko and Norton (2007) say that when L2 learners feel themselves belong to the target language community, this feeling motivates them rapidly and consequently builds their self-confidence to achieve their desired goal in the shortest time.

Based on the afore-mentioned theories, it is clear that self-confidence is one of the most dominant factors in L2 acquisition. The concept of self confidence in L2 acquisition was first focused through the social context model of Clement (1980; 1986). He considered self-confidence as a vehicle to remove L2 learners' language anxiety. According to Clement (1980), when SLA takes place in multicultural atmosphere and L2 learners get chance to engage themselves in communication with target language community, this opportunity assists them build their self-confidence and it forces them to be more motivated to learn the $L 2$ in the fastest way. Besides, willingness to communicate (WTC) is another social psychological model of SLA introduced by Maclntyre et al. (1998), where they put self-confidence as the pivotal factor of L2 learning. The WTC model says that learners' willingness to communicate is the outcome of a number of social psychological, linguistic and communicative variables which lead them to learn the L2 spontaneously. WTC is affected differently by both anxiety and perceived competence. WTC is grown in L2 learners when they are driven with self-confidence which forces them learn quickly. There are two phases of self-confidence based on time and situations; trait-like self-confidence and state self-confidence which are distinguished from one another by Maclntyre et al. (1998).

Being considered as a part of social psychological variable, some studies have replaced selfconfidence with self-efficacy which helps create motivation and language acquisition (e.g., Chularut \& DeBacker, 2004; Cotterall, 1999; Ehrman et al., 2003; Oliver et al., 2005). But Tremblay and Gardner (1995) have made distinction between self-confidence and self-efficacy mainly in light of the inclusion of an anxiety component. In L2 learning situation, analysing the work of Clement and others related to him, it is evident that self-confidence is a part of motivation that makes a difference between individuals in terms of learning L2 (Ellis, 1994). So, before the visibility of Norton's work about selfconfidence, there were very few studies that highlighted the ways through which learners' selfconfidence could be constructed. Norton $(1995,1997,2000)$ explained a clear concept on how learners can gain self-confidence and how they can use English language in the actual situation outside of their classroom with the courage of self-confidence and also formed the social constructive view of self-confidence implying that both the factors, anxiety and self-confidence are the results of environmental influence and the lived experiences of the learners.

Hence, after synthesizing the findings and observations of existing studies, this study has drawn a conceptual framework that would guide it to have a better understanding of various factors that influence $L 2$ learners' self-confidence and consequently helps them develop their language skills. Figure 1 in the following exhibits the conceptual framework of this study: 


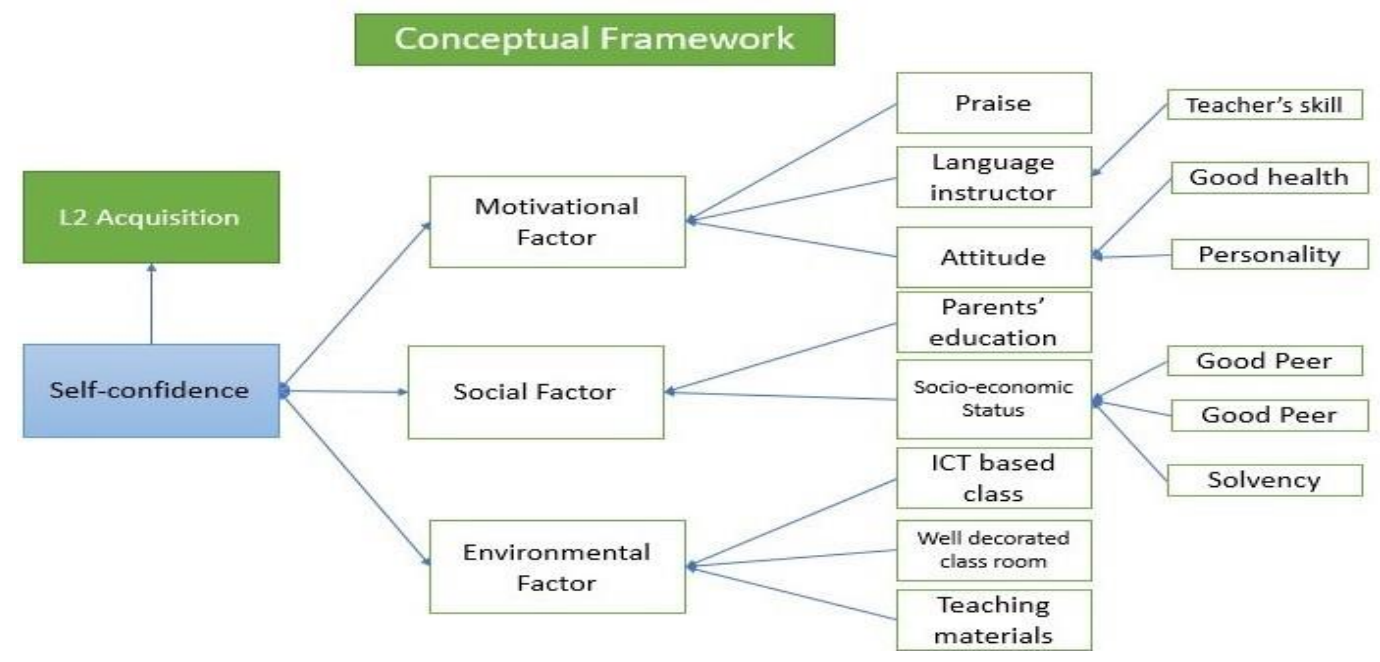

Figure 1: Conceptual Framework

\section{METHODOLOGY}

Since the present study deals with getting an in-depth understanding of factors associated with building learners' self-confidence in SLA, a qualitative case study has been deployed to have the desired outcome of the study. For getting an accurate understanding of the event, the steps and procedures of data collection, transcription, and interpretation have been given due importance.

\section{Data Collection Method}

An in-depth interview protocol was taken into consideration for this qualitative research. A set of semi-structured interview questions was used to get the necessary data. As the COVID-19 pandemic is still in rise, all kinds of educational institutions in Bangladesh are physically closed. However, many institutions are carrying out their operations through the use of virtual platforms. Due to the closure of the universities, data were collected through interviews over phone. The participants were primarily urged to portray their experience regarding the impact of self-confidence on SLA. Then they were asked several questions in order to find out the factors that enhance their self-confidence level to learn L2. With the prior permission of the respondents, their interviews were audio-recorded through the use of audio-recorder apps. The interviews were taken in October 2020.

\section{Participants}

For a qualitative case study, a purposive sample was used to have a clear understanding of the phenomenon. In line with this view, 13 students from two renowned private universities located in Chittagong, Bangladesh were chosen as the participants. The selection of the sampling is done considering time, money, location, availability of sites or respondents, and so on. To select the respondents, those students were given priority who have already completed their postgrad as they can give the real voice regarding the aim of this study. Reason behind choosing private university students was that in the context of Bangladesh, private university students are thought to be less competent compared to their counterpart public university students. Out of 13 respondents, 7 were 
from one university and 6 from another university while 7 of them were male and the rest were female. They were in between 23 and 27 years of age while they were interviewed.

\section{Data Analysis}

The conceptual framework of this study was taken into consideration to analyse the data of this study. As said earlier that interviews were audio-recorded through audio-recording apps in the mobile phone. The audio-recorded interviews were interpreted quickly, and the researchers assessed every record with composed notes from the interview while listening to the relating tape. To ensure the validity and reliability of the study, the transcribed data have been sent to the respondents to get their ratification whether the researchers recorded the things exactly what they said

\section{FINDINGS AND DISCUSSIONS}

The conceptual framework of this study which has been developed following the frameworks of Maclntyre et al. (1998), Clément (1980; 1985) and Rubio (2007) shows that learners self-confidence depends on mainly three factors- motivational factor, social factor, and environmental factor. These factors have also many sub-factors that can have a great impact on self-confidence either positively or negatively. Feeling of being capable of doing anything is considered as self-confidence. A man who has competency to do a job, but cannot initiate it because of low level of self-confidence is seen unsuccessful in the long-run. Similarly, a learner having good skill in language might feel that he cannot speak before others in the classroom can be regarded as the lack of self-confidence. Self-confidence is a mental representation or the sense of cognition similar to fear and anxiety in human being. Rubio (2007) considered cognition as the centre of self-confidence, that failure or success is felt cognitively. There are many factors which lead a person to fear or anxiety, and in the same way there are also many determiners/factors/variables that are responsible in the increase and decrease of learners' selfconfidence. However, the current study investigates factors associated with augmenting the level of learners' self-confidence in SLA. Hence, the collected data of this study presents factors associated with accelerating learners' self-confidence in SLA. The development of learners' self-confidence has been accounted through mainly three factors as depicted by the conceptual framework stated above. These three factors are illustrated below based on the experiences of the respondents interviewed for this research. Among these three, empirical data shows motivational factor is the main driving force to build L2 learners' level of self-confidence.

\section{Motivational Factor}

Motivation is that driving force in SLA that enables learners to learn the language in a rapid manner. Richards (1985) considers motivation as a force that creates a person's feeling to do something. Research also shows that invested learners can acquire the language more quickly than the non-invested learners. Motivation can be intrinsic or extrinsic, integrative or instrumental. All kinds of motivation together build learners' self-confidence. Motivational factor depends on three things, such as, praise from the teacher or from others, the quality and attitude of the language instructor. Praise can enhance the learners' self confidence to learn the $L 2$ in a quick manner. This is the general philosophy of the learners that they will commit mistakes. Nonetheless, if the teachers, being their facilitators, show their positive attitudes to them by telling them motivating words like 'no problem, you can', learners will get hope and they can produce more sentences by removing their 
shyness and nervousness. So, praise can be a great factor to create motivation and self-confidence of the learners. In this regard, $80 \%$ of the total respondents say,

When we do any mistakes in speaking or writing in English, our teachers inspire us saying the words like it's not a matter, failure is the pillar of success etc. which motivate us to learn English easily and our enthusiasm of learning gets accelerated.

So, after analysing the empirical data based on the above factor, it is certain that teachers' praise plays a significant role in building up the self-confidence of a learner to learn the target language. This finding is aligned with the findings of Selvi \& Martin-Beltrán (2016) and Bao \& Liu (2021).

Besides, learners feel highly motivated when they find very skilled and outstanding language teachers. There are some language instructors who can not speak fluently and pronounce properly. This creates demotivation among students. If the teachers are skilled equally in all the skills of language and can teach properly, students become more concentrated in the class and try to be as proficient as the teacher and this leads them to be self-confident. Teachers' good attitude and behaviour can also build self-confidence of the learners. The respondents of this study agreed that the mentioned motivational factors have an influence on learners' self-confidence. In this note, 12 out of total 13 respondents agree with this as they state,

When we see our teachers speak very fluently and their personality is good, we try our utmost to be like him/her and accelerate our oral proficiency in English.

From this view, it is obvious that teachers' skill and proficiency level play a vital role in developing the self-confidence of a learner. Other studies (e.g., Izumi \& Bigelow, 2000; Rastelli, 2018; Bao \& Liu, 2021) also find that EFL teachers' proficiency, pronunciation, and overall linguistic knowledge motivate learners to develop their level of self-confidence that consequently makes them communicatively competent.

However, very few respondents opine their views in a different tone. They say that their teachers sometimes rebuke them when they commit any mistakes, and they utter local dialect in the classroom which hinders to build their self-confidence. In this context, 3 of the participants say,

Sometimes we get rebuked by our teachers if we do any mistakes in English. Besides, some of our teachers utter local dialect in the classroom which decreases our self-esteem in learning English.

The above statement shows that teachers' behavior with the learners can affect learners' selfconfidence either positively or negatively. If they scold learners, negative results are found. This finding is aligned with the findings of Islam (2017) and Izumi \& Bigelow (2000).

\section{Social Factor}

Secondly, the findings of this empirical study show that social factor is another key player that helps L2 learners build their self-confidence. Social factor can be based on parents' education and socio-economic status of the learners. Sometimes learners' self-confidence is correlated with the outlook of the parents. At present time, parents' education can be a great motivational factor for the learners. It is seen that those learners can learn more quickly whose parents are more educated than those whose parents are less educated. Beside these, parents' care, attachment, and love can 
influence learners' self-confidence. So, L2 learners can be influenced for the development of their self confidence by their parents from various perspectives. $70 \%$ of the respondents opine their positive views in support of this as they state,

It stimulates our learning when we see our parents are more educated compared to our other friends'. Moreover, we can practise speaking with our parents.

Similar notion is found from the studies of Yamamoto, Holloway \& Suzuki (2016) and Moneva et al. (2020) where they show how parents influence L2 learners' learning zeal.

Another important factor is socio-economic status of the learner. In the current age, almost all the things are given standard based on the socio-economic status of a person. Those who possess more money are highly valued and respected in the society. If the parents are financially solvent enough, they can send their children to the good English medium schools which are comparatively teach better than other schools. Parents without having standard economic solvency can not send their children to the best schools, as a result their children do not get as much opportunity to learn the $L 2$ as rich children get. So, students with high socio-economic status always feel more motivated and confident than those of the poor's as all the participants show their affirmative consent in this regard by stating,

When our parents are financially solvent and they can invest a good portion of their earning behind our education, this gives us pleasure and enhances our confidence level to learn the L2.

So, to conclude the explanation of this above statement, it is worthy to acknowledge that parents' educational as well as economic status motivate a learner greatly in learning L2. Similar finding are visible by the study of Liu G, Teng X and Zhu D (2019). Other studies such as Elliot and McGregor (2001), Grant and Dweck (2003) and Wang \& Wu (2020) also denote that learners' motivation gets influenced by their parents' socio-economic status.

\section{Environmental Factor}

Then environmental factor is another most important one for the development of the selfconfidence of the $L 2$ learners. In terms of teaching-learning $L 2$, environmental factor depends on other sub factors like, ICT based teaching, well decorated classroom and teaching materials. To transform the conventional teaching concept into modern and time-tested teaching that is learners centred and interactive, there is no alternative to use ICT in teaching. The necessity of the use of ICT in the language class is totally undeniable. Computer, internet line, multimedia projector are the foundation of a smooth ICT based classroom without which it's unimaginable. Modern aged learners are ICT/technology friendly. They are prone to learn from technology and an ICT based classroom can meet up the demand these learners. As they find what they expect the classroom to be, so they feel motivated, and this turns them to build their self-confidence. On the other hand, lack of ICT facilities in the classroom causes lack of self-confidence that affects their learning.

Well decorated classroom can be another factor of motivation and building self-confidence. Well decorated classroom refers to the classroom where there is teaching conducive environment. There are the availability of those things which help learners in smooth learning, such as, chair, desk, fan, light, AC, ventilation and so on. It is seen that those classrooms can attract learners in learning highly which have all kinds of modern and teaching friendly amenities and attraction or fascination for 
learning help learners build their self-confidence. On the other hand, where there is the absence of these amenities, students feel less interest in the classroom, rather they feel bored which leads them to demotivation that results in lack of self-confidence.

To me last but not the least, another important factor to build self-confidence is teaching materials. At present we mostly try to implement CLT in learning English that requires the authentic teaching materials which will be based on real life situation and practical experiences of the learners. But still we notice, the books taught for CLT are based on Grammar Translation (GT) method which are the cause of learners' demotivation. It is seen that authentic and real-life based teaching materials create learners' interest in learning which as a result builds motivation and their self-confidence. Almost $90 \%$ of the total participants of this study viewed that the stated environmental factors have an effect on building learners' self-confidence in SLA. In this regard, they say,

In our previous class, the overall environment including infrastructure facility was not up to the mark that compelled us to be absent-minded. But in our next year, when we found congenial atmosphere of education, we got highly motivated that augmented our self-confidence level and we learnt $L 2$ so fast. Moreover, we were provided with updated teaching materials in our library. When we faced any problem about teaching -learning materials, we got it in our enriched library.

From the above statements, it is apparent that environmental factors play a significant role in improving the self-confidence of a learner to learn L2. This notion is supported by the findings of Hori \& Fujii (2021). However, $50 \%$ of the participants expressed their frustration regarding environmental facilities. They say that their classrooms were not equipped with ICT facilities and well decorated. Besides, they did not have adequate proper learning materials. As a result, they could not learn $L 2$ properly. In this context, one of the respondents states,

Our classrooms were not ICT based and well decorated. We did not get updated books in our library for learning a new thing.

So, after scrutinizing the empirical data from the above statements, it is certain that teaching materials as well as enriched library including physical environment of the classroom help learners greatly in building up the self-confidence to learn the $L 2$. Such findings have a correlation with the findings of Islam (2017) and Kung (2019) who have shown an undeniable importance of environmental factors in accelerating learners' learning zeal.

\section{CONCLUSION WITH POLICY RECOMMENDATIONS}

The findings of this qualitative study show that self-confidence of learners relies on some affective factors like social, motivational and environmental factors that motivate them learn any foreign language easily. The teachers of $\mathrm{L} 2$ can apply various techniques to make their classroom congenial so that the learners become enthusiastic to learn the target language neglecting their anxieties and tension. Learners should also know the way of learning those affective factors avoiding the factors' negative impact and use the innate subjectivity to learning the L2. It is not an easy task for the second language teachers to bridge up the gap of the self-confidence of the students from lower level to highest level. So, it is recommended that they should engage themselves in ceaseless studies as well as innumerable practices. In addition, teachers can likewise furnish themselves with more educational strategy and psychosomatic knowledge, and try unlimited attempts to expand L2 learners' 
self-confidence, bring down their anxieties, stimulate their inspiration, and improve their learning efficacy. As this paper deals with a qualitative study with only thirteen respondents, so it does not come out with the proper solution. The future researchers are suggested to conduct both qualitative and quantitative research on this gap by considering larger sample size so that they may go into deep on how to build L2 learners' self-confidence level.

\section{CONFLICTS OF INTEREST}

There are no conflicts to declare.

\section{REFERENCES}

[1] Arkoudis, S., \& Davison, C. (2008). Chinese students: Perspectives on their social, cognitive and linguistic investment in English medium interaction. Journal of Asian Pacific Communication, 18(1), 3-8.

[2] Bandura, A. (1993). Perceived Self-Efficacy in Cognitive Development and Functioning. Educational Psychologist 28(2): 117-148.

[3] Bao, Y. Y., \& Liu, S. Z. (2021). The Influence of Affective Factors in Second Language Acquisition on Foreign Language Teaching. Open Journal of Social Sciences, 9, 463-470.

[4] Barkhuizen, G. (2004). Social influences on language learning. In A. Davies \& C. Elder (Eds.), The handbook of applied linguistics (pp. 552-575): Blackwell Publishing.

[5] Bourdieu, P. (1991). Language and symbolic power. Cambridge: Polity Press in association with Basil Blackwell.

[6] Chemers, M.M., Watson, C.B., May, S.T. (2000). Dispositional Affect and Leadership Effectiveness: A Comparison of Self-Esteem, Optimism, and Efficacy. Personality and Social Psychology Bulletin 26(3): 267-277.

[7] Chularut, P., \& DeBacker, T. K. (2004). The influence of concept mapping on achievement, selfregulation, and self-efficacy in students of English as a second language. Contemporary Educational Psychology, 29, 248-263.

[8] Clark, R.A., Goldsmith, R.E., Goldsmith, E.B. (2008). Market mavenism and consumer selfconfidence. Journal of Consumer Behaviour 7(3): 239-24

[9] Clément, R. (1980). Ethnicity, contact and communicative competence in a second language. In H. Giles, W. R. Robinson \& P. M. Smith (Eds.), Language: Social psychological perspectives (pp. 147-154). Oxford: Pergamon.

[10] Clément, R., \& Kruidenier, B. (1985). Aptitude, attitude and motivation in second language proficiency: A test of Clément's model. Journal of Language and Social Psychology, 4, 21-37.

[11] Cotterall, S. (1999). Key variables in language learning: What do learners believe about them. System, 27, 493-513.

[12] Dessi, R., \& Zhao, X. (2011). Self-esteem, shame and personal motivation. Q. J. Econ. 117(3), 871-915.

[13] Douglas, B. H. (2014). Principles of Language and Teaching (6th ed.). White Plains, NY: Pearson Education.

[14] Ehrman, M., Leaver, B. L., \& Oxford, R. (2003). A brief overview of individual differences in second language learning. System, 31, 313-330.

[15] Elliot AJ, McGregor HA (2001). A 2 X 2 achievement goal framework. J. Pers. Soc. Psychol. 80:501-519.

[16] Ellis, R. (1994). The study of second language acquisition. Oxford University Press.

[17] Erol, R.Y., Orth, U. (2011). Self-esteem development from age 14 to 30 years: A longitudinal study. Journal of Personality and Social Psychology 101(3): 607-619. 
[18] Eryaman, Y., Koçer, Ö., Kana, F., \& Şahin, Y. E. (2013). A transcendental phenomenological study of teachers' self efficacy experiences. Cadmo: GiornaleItalianoDi Pedagogia Sperimentale, 21(2), 9-33.

[19] Gardner, R. C., Tremblay, P. F.\& Masgoret, A. M. (1997). Towards a full model of second language learning: An empirical investigation. The Modern Language Journal,81(iii), 344-362.

[20] Ghasemi, A. A. (2018). Ideal L2 self, visual learning styles, and L2 self confidence in predicting language proficiency and L2WTC: A structural equation modeling. English Teaching \& Learning, 42(2), 185-205.

[21] Ghasemi, A. A., Ahmadian, M., Yazdani, H., \& Amerian, M. (2020). Towards a model of intercultural communicative competence in Iranian EFL context: Testing the role of international posture, ideal L2 self, L2 self-confidence, and metacognitive strategies. Journal of Intercultural Communication Research, 49(1), 41-60.

[22] Heine SJ, Kitayama S, Darrin RL (2001). Cultural differences in selfevaluation. J. Cross-Cultural Psychol. 32(4):434-443.

[23] Hori, R.; Fujii, M. (2021). Impact of Using ICT for Learning Purposes on Self-Efficacy and Persistence: Evidence from Pisa 2018.Sustainability, 13, 6463.

[24] Islam, R. (2017). Investigating Factors That Contribute to Effective Teaching-Learning Practices: EFL/ESL Classroom Context. English Language Teaching, 10(4), 15-21.

[25] Izumi, S., \& Bigelow, M. (2000). Does output promote noticing and second language Acquisition? Tesol Quarterly, 34(2), 239-278.

[26] Kung, F. W. (2019). Teaching second language reading comprehension: the effects of classroom materials and reading strategy use. Innovation in Language Learning and Teaching, 13(1), 93 104.

[27] Lavadores, A. K. C., Escobedo, P. S., \& Sosa, J. P. (2017). Academic Self- efficacy of High Achieving students in Mexico. Journal of Curriculum and Teaching, 6(2), 84-89.

[28] Lenahan, P. (2015). The Uses of Amateurs: Travel Writing as a Tool of Second Language Acquisition Research. English Academy Review, 32(1), 140-151.

[29] Lin, A., Wang, W., Akamatsu, N., \& Riazi, A. M. (2002). Appropriating English, expanding identities, and re-visioning the field: From TESOL to teaching English for globalized communication (TEGCOM). Journal of Language, Identity, and Education, 1(4), 295-316.

[30] Liu G, Teng X and Zhu D (2019). Effect of Self-Esteem and Parents' Psychological Control on the Relationship Between Teacher Support and Chinese Migrant Children's Academic Achievement: A Moderated Mediation. Front Psychol. 10, 23-42

[31] MacIntyre, P. D., \& Vincze, L. (2017). Positive and negative emotions underlie motivation for L2 learning. Studies in Second Language Learning and Teaching, 7(1), 61-88.

[32] MacIntyre, P. D., Clément, R., Dörnyei, Z., \& Noels, K. A. (1998). Conceptualizing willingness to communicate in an L2: A situated model of confidence and affiliation. Modern Language Journal, 82, 545-562.

[33] MacIntyre, P. D., Gregersen, T., \& Mercer, S. (2019). Setting an agenda for positive psychology in SLA: Theory, practice, and research. The Modern Language Journal, 103(1), 262-274.

[34] Maftoon, P., \& Ziafar, M. (2013). Effective factors in interactions within Japanese EFL classrooms. The Clearing House: A Journal of Educational Strategies, Issues and Ideas, 86(2), 74-79.

[35] Moneva, J.C., Linive C. Japos \& Rosalie L. Ohayas. (2020). Parental Motivation and Achievement. International Journal of Social Science Research, 8(2), 102-115.

[36] Mutluer, S. (2006). The role of moral values in forming self-confidence. Graduated thesis. Ankara University, Social Sciences Institute, Ankara, Turkey. 
[37] Norton, B. (1997). Language, identity and the ownership of English. TESOL Quarterly, 31(3), 409429.

[38] Norton, B. (2000). Identity and language learning: Gender, ethnicity and educational change. Pearson Education Limited.

[39] Norton, B., \& Gao, Y. (2008). Identity, investment and Chinese learners of English. Journal of Asian Pacific Communication, 18(1), 109-120.

[40] Norton, P. B. (1995). Social identity, investment, and language learning. TESOL Quarterly, 29, 931.

[41] Nui, L. (2016). Parental Motivational Practice, Parent Involvement, and Students' Choice of Study Field in College. World Journal of Education, 6(5).

[42] Oliver, R., Purdie, N., \& Rochecouste, J. (2005). Affective Aspects of Foreign Language Learning: Beliefs, Attitudes, and Efficacy. Babel, 40(2), 29-38. 268

[43] Ozdemir, E., \& Papi, M. (2021). Mindsets as sources of L2 speaking anxiety and self-confidence: the case of international teaching assistants in the US. Innovation in Language Learning and Teaching, 1-15.

[44] Park, L.E., \& Crocker, J. (2005). Interpersonal Consequences of Seeking Self-Esteem. Personality and Social Psychology Bulletin, 31(11), 1587-1598.

[45] Park, L.E., Crocker, J., \& Kiefer, A.K. (2007). Contingencies of Self-Worth, Academic Failure, and Goal Pursuit. Personality and Social Psychology Bulletin, 33(11), 1503-1517.

[46] Pavlenko, A. (2002). Poststructuralist approaches to the study of social factors in second language and use. In V. Cook (Ed.), Portraits of the L2 user (pp. 275-302). Clevedon: Multilingual Matters.

[47] Pavlenko, A., \& Norton, B. (2007). Imagined communities, identity, and English language learning. In J. Cummins \& C. Davison (Eds.), International handbook of English language teaching (pp. 669-680). New York: Springer Science and Business Media, LLC.

[48] Pennycook, A. (1999). Introduction: Critical approaches to TESOL. TESOL Quarterly, 33, 329348.

[49] Rastelli, S. (2018). Neurolinguistics and second language teaching: A view from the crossroads. Second Language Research, 34(1), 103-123.

[50] Richards. J, Platt. J, \& Weber. H. (1985). Longman Dictionary of Applied Linguistics. England: Longman.

[51] Rubio, F. (2007). Self-esteem and foreign language learning, introduction. Cambridge Scholars Publishing: Cambridge.

[52] Selvi, A. F., \& Martin-Beltrán, M. (2016). Teacher-learners' engagement in the reconceptualization of second language acquisition knowledge through inquiry. System, 63, 28-39.

[53] Sugita McEown, M., Sawaki, Y., \& Harada, T. (2017). Foreign language learning motivation in the Japanese context: Social and political influences on self. The Modern Language Journal, 101(3), 533-547.

[54] Timirli, K. B. (2013). Therapy. Marmara Education institution, guidance and counseling center, İstanbul, Turkey.

[55] Tremblay, P., \& Gardner, R. C. (1995). Expanding the motivation construct in language learning. The Modern Language Journal, 79(iv), 505-520.

[56] Wang, Linyan., \& Wu, Xuan. (2020). INFLUENCE OF AFFECTIVE FACTORS ON LEARNING ABILITY IN SECOND LANGUAGE ACQUISITION. Revista Argentina de Clínica Psicológica; Buenos Aires. 29(2),1232.

[57] Yamamoto, Y., Holloway, S. D., \& Suzuki, S. (2016). Parental Engagement in children's education: Motivating Factors in Japan and the U.S. School Community Journals, 26(1). 
[58] Young, R. F. (2007). Language learning and teaching as discursive practice. In H. Zhu, P. Seedhouse, W.Li, and V. Cook (Eds.), Language learning and teaching as social inter-action (pp. 251-271). Palgrave Mcmillan.

[59] Zhu, H., Seedhouse, P., Li, W., \& Cook, V. (Eds.). (2007). Language Learning and Teaching as Social Inter-Action. Palgrave Macmillan

[60] Zuengler, J., \& Miller, E. R. (2006). Cognitive and sociocultural perspectives: Two parallel SLA worlds? TESOL Quarterly, 40(1), 35-58

(C) 2021 by ICRRD, Kuala Lumpur, Malaysia. All rights reserved. This article is an open access article distributed under the terms and conditions of the Creative Commons Attribution(CC BY) license (http://creativecommons.org/licenses/by/4.0/). 